\title{
Study on the Ejective Debris of Granite Biaxial Rockburst Test
}

\author{
Shicheng Tang ${ }^{1, a}$, Xinjin Liu ${ }^{1}$ Kang Chen ${ }^{1}$ \\ ${ }^{1}$ School of Civil and Architecture Engineering, Guangxi University, Guangxi 530004, China. \\ a1303788308@qq.com
}

Key words: granite; biaxial rock burst; ejection of debris; particle size distribution; geometric characteristics.

\begin{abstract}
Using the self-developed real triaxial rock burst experimental system and the established rockburst experiment method, the rockburst experiment of granite with different loading types was carried out. Ejection fragments were screened and carried out statistics, and the particle size distribution of the ejection fragments under different loading types was obtained. The size of crumb is divided into coarse granular, medium granular, fine granular and granular debris, and the scale ratio of coarse granular debris is calculated. The geometrical characteristics of ejection fragments of granite biaxial rockburst test under different loading types were compared, and the similarities and differences were found. The research results can be used as the basis for identification of biaxial rockburst and identification of rockburst.
\end{abstract}

\section{Introduction}

Under high stress condition, brittle rock is prone to rockburst damage. At present, with the development of underground rock engineering, the problem of rockburst disaster is becoming more and more prominent. Rockburst is a special form of rock damage. It is a phenomenon of hard rock dynamic destruction, which is characterized by high-speed ejection or throwing of rock fragments. It poses a serious threat to the life of construction workers, the safety of construction equipment and the progress of construction[1-2]. Therefore, the rockburst detritus analysis has important theoretical and practical significance.

For the rockburst detritus, the geometry (scale and shape) of the rockburst is mainly analyzed and studied[3-5]. At present the research methods of ejecting debris mainly include: screening method, experience formula method, photography method, etc. K.Shivakumar et al [7] studied the rockburst size by assuming that the rockburst has self-similarity. He Manchao et al. have classified the debris after the rock burst experiment[6]. The traditional research on detritus is mainly focused on rock masses with different loading rates and different component sizes, and has not yet conducted the comparative analysis of rockburst detritus of different loading types (impact, cyclic loading, micro disturbance). The research on rockburst detritus of different loading types can deepen the understanding of biaxial rockburst and provide a more accurate criterion for rockburst type.

In this paper, according to the established rockburst test method, the self-developed real triaxial rockburst experiment system was used to carry out the biaxial rockburst test of different loading types of granite under impact load, cyclic load and perturbation load, and the rockburst detritus was obtained under laboratory conditions. The scale characteristics of rockburst detritus of different loading types were analyzed and compared. Through the tests of different loading types, and based on the analysis of the distribution characteristics of the ejection clast size, the biaxial rock burst detritus is displayed intuitively by quantitative research, so as to provide a basis for deepening understanding of biaxial rock burst.

\section{Rockburst test}

\subsection{Rock specimen preparation and the main physical and mechanical parameters}

The red coarse grained granite samples were taken from Cenxi City, Wuzhou, Guangxi. To reduce the effect of discreteness of rock samples on the test results, large and homogeneous intact rock blocks 
were selected as test materials. Cube specimen size is $100 \mathrm{~mm} \times 100 \mathrm{~mm} \times 100 \mathrm{~mm}$ with smooth surface, flesh red color, no obvious defects, unevenness and non-perpendicularity are less than $0.05 \mathrm{~mm}$. The velocity of longitudinal wave is about $5.6 \mathrm{~km} / \mathrm{s}$, the integrity and uniformity are good, the average density is $2591 \mathrm{~kg} / \mathrm{m} 3$.

\subsection{Test equipment}

In this paper, the testing machine is developed by Guangxi University with high pressure servo dynamic true triaxial testing machine. The test machine vertical maximum load pressure is up to $5000 \mathrm{kN}$, and the upper limit of the two horizontal loading pressures is $3000 \mathrm{kN}$. Loading and unloading control with full digital servo control can be carried out in three independent vertical load. Test control system configuration includes acoustic signal monitoring, LVDT deformation sensing measurement system, to ensure that stress loading and displacement under the load are in two ways of precise control. Rockburst detonation damage tracking process used the United States SVSI GigaView Series GVCM08-B05 high-speed camera system and the British IMETRUM series IM-VG03-1-117B high-speed camera system, the arrangement of the high-speed camera system is shown in Fig 1.

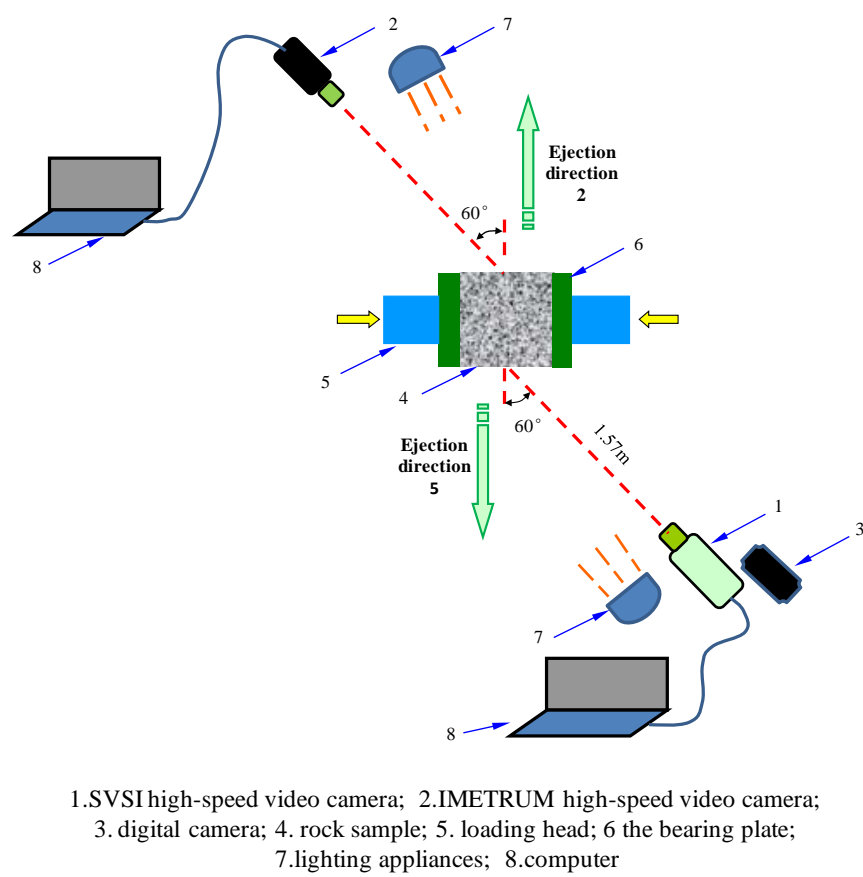

\subsection{Test scheme}

Fig.1 High-speed camera system layout

The biaxial rockbursts of three types (shock, cyclic loading, micro disturbance) are considered. Using stress loading method, a horizontal lateral pressure of $30 \mathrm{MPa}$ was applied to the test piece at a speed of $5000 \mathrm{~N} / \mathrm{s}$ using a separate horizontal lateral loader and remained constant.

Table 1 experimental scheme

\begin{tabular}{|c|c|c|c|c|c|c|}
\hline No. & Type of test & $\sigma \mathrm{z}(\mathrm{MPa})$ & $\begin{array}{c}\sigma \mathrm{x} \\
(\mathrm{MPa})\end{array}$ & $\mathrm{f}(\mathrm{Hz})$ & $\mathrm{A}(\mathrm{kN})$ & Remarks \\
\hline SY3 & $\begin{array}{c}\text { biaxial impact } \\
\text { rock burst test }\end{array}$ & $0.85 \sigma \mathrm{z} \sim 0.90 \sigma \mathrm{z}$ & 30 & & & \\
\hline SY7 & $\begin{array}{c}\text { biaxial cyclic } \\
\text { loading test }\end{array}$ & $0.85 \sigma \mathrm{z} \sim 0.90 \sigma \mathrm{z}$ & 30 & 1 & 400 & \\
\hline SY9 & $\begin{array}{c}\text { rockburst Test of } \\
\text { Z - disturbance }\end{array}$ & $0.85 \sigma \mathrm{z} \sim 0.90 \sigma \mathrm{z}$ & 30 & 15 & 20 & \\
\hline
\end{tabular}

Tests of each loading type were repeated for 3 groups, and representative tests were selected as the mean values. 


\section{Classification and characteristics of rock burst}

\subsection{Classification of rockburst in different loading}

The results show that different types of loading, rock the ejection of clastic rock burst occurred is different in size, shape, etc. According to clastic rock burst size, quality and other measurable physical quantities, rockburst detritus of different loading types are classified.

For the measurable physical quantities of the rockburst, the ejection fragments collected in the test are screened using standard sieves with mesh diameters of 9.5, 4.75, 2.36, 1.18, 0.6, 0.3, 0.15 and $0.075 \mathrm{~mm}$ respectively, nine particle size group are obtained; The particles were classified into coarse particles $(d \geq 9.5 \mathrm{~mm})$, medium particles $(4.75 \mathrm{~mm} \leq \mathrm{d}<9.5 \mathrm{~mm})$, fine particles $(0.075 \mathrm{~mm}<\mathrm{d}$ $<4.75 \mathrm{~mm}$ ) and particles ( $<0.075 \mathrm{~mm}$ ) ) Four grain-size groups; The mass of each group of grains was weighed with a high-sensitivity electronic scale. The maximum length, the maximum width and the maximum thickness of coarse-grained debris are measured with vernier caliper. The partial ejection debris accumulation in the two-axis rockburst test of different loading types is shown in Fig. 2.

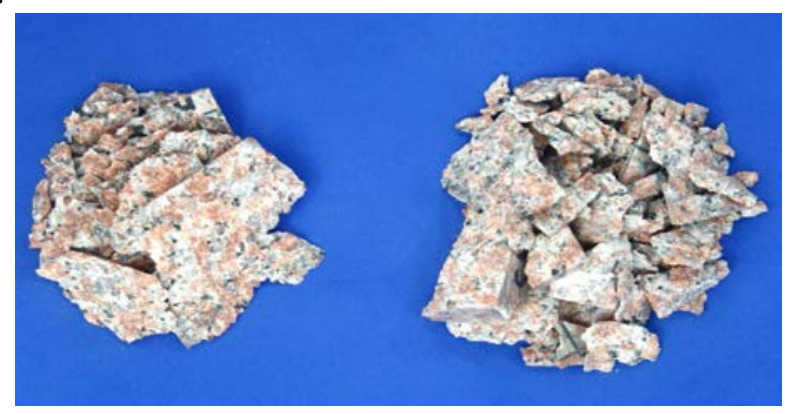

(a) Impact load

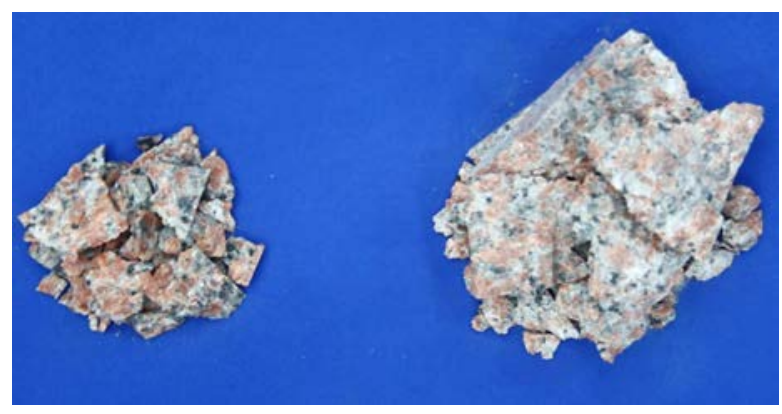

(c) Micro-perturbation

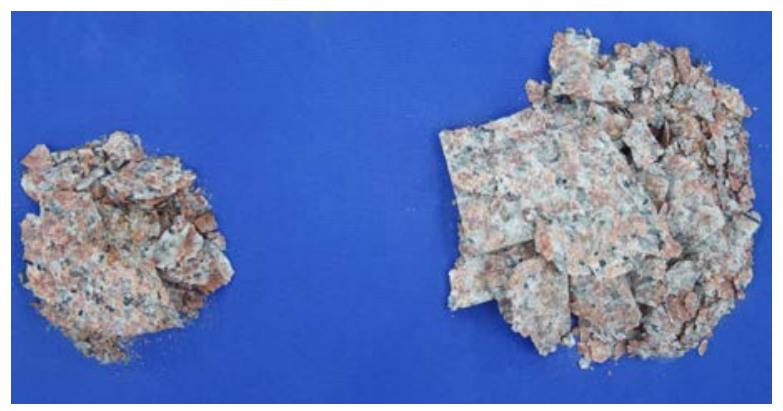

(b) Cyclic loading

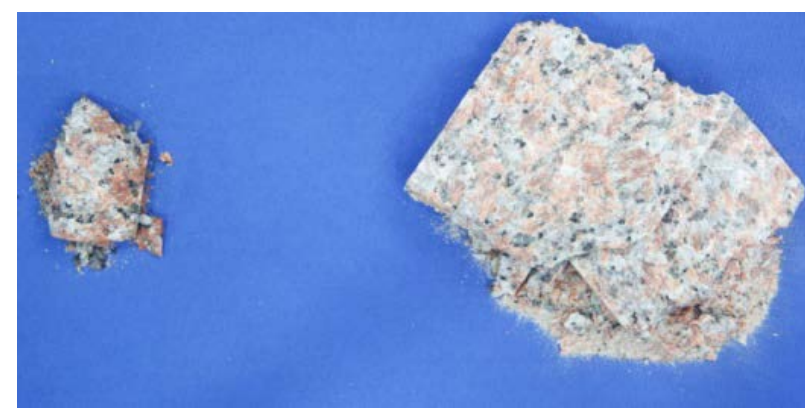

(d) Static loading

Fig.2 Detrital morphology of granite biaxial rock burst in different loading

\subsection{Characteristics of ejecting debris}

In two-axis rockburst experiments with different loading types, the characteristics of ejection fragments in two directions are different in direction 2 and direction 5, and can be described from two aspects: scale and shape.

The scale feature is the most basic characteristic of rockburst detritus. For more accurate grasp of scale characteristics of rockburst detritus, the maximum length, the maximum width and the maximum thickness are measured with vernier caliper for ejection debris with grain size $\geq 9.5 \mathrm{~mm}$.

The shape feature is an important information that the rockburst detritus can easily be observed and acquired. through the scale characteristics of the basic measurement data processing, Length and width ratio, length and thickness ratio and width and thickness ratio of ejection clastic rock burst are calculated. According to the length and thickness ratio of rock fragments, rockburst detritus is divided into four types, namely: massive debris, length and thickness ratio $<3$; plate-like debris, length and thickness ratio of 3 to 6; flake debris, length and thickness ratio of 6to 9; and Laminar clastic length and thickness ratio $>9$. According to the average value of the debris scale, the proportion of the scale of rock debris, which is representative of different failure forms, can be 
determined by the above method, ie the ratio of length, width and thickness, and the corresponding representative size ratios are obtained to represent the scale characteristics of rockburst detritus.

For small debris of $d<9.5 \mathrm{~mm}$, because of its numerous and not easy to measure, therefore, the method of calculating the percentage of the quality of each particle size after sieving is applied for its description. The results of mass statistics show that the ejection fragments with diameter $\mathrm{d} \geq 9.5 \mathrm{~mm}$ account for $83 \%, 74 \%, 81 \%, 84 \%$ of the total mass, respectively, in the two-axis rockburst tests under impact loading, cyclic loading, micro-perturbation and static loading. And the particle size $\mathrm{d}<9.5 \mathrm{~mm}$ of the small debris of the mass distribution are also different, in some grain size difference is large. The mass distribution of the rockburst detritus under disturbed loading and cyclic loading is shown in Fig.3.

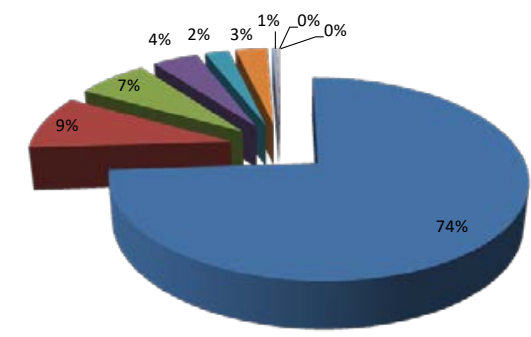

- $\mathrm{d} \geq 9.50 \mathrm{~mm} \quad 4.75 \mathrm{~mm} \leq \mathrm{d}<9.50 \mathrm{~mm}=2.36 \mathrm{~mm} \leq \mathrm{d}<4.75 \mathrm{~mm}$ $-1.18 \mathrm{~mm} \leq \mathrm{d}<2.36 \mathrm{~mm}=0.60 \mathrm{~mm} \leq \mathrm{d}<1.18 \mathrm{~mm}=0.30 \mathrm{~mm} \leq \mathrm{d}<0.60 \mathrm{~mm}$ $=0.15 \mathrm{~mm} \leq \mathrm{d}<0.30 \mathrm{~mm}=0.075 \mathrm{~mm} \leq \mathrm{d}<0.15 \mathrm{~mm} \Perp \mathrm{d}<0.075 \mathrm{~mm}$

(a) disturbed loading rockburst

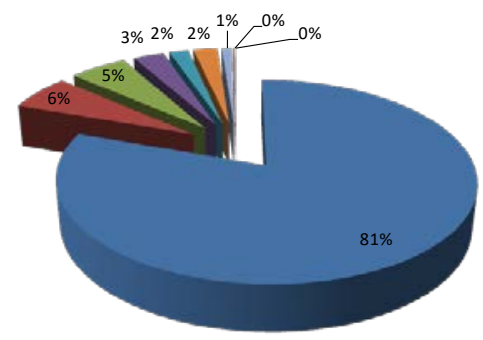

$=\mathrm{d} \geq 9.50 \mathrm{~mm} \quad \quad=4.75 \mathrm{~mm} \leq \mathrm{d}<9.50 \mathrm{~mm}=2.36 \mathrm{~mm} \leq \mathrm{d}<4.75 \mathrm{~mm}$ $=1.18 \mathrm{~mm} \leq \mathrm{d}<2.36 \mathrm{~mm}=0.60 \mathrm{~mm} \leq \mathrm{d}<1.18 \mathrm{~mm}=0.30 \mathrm{~mm} \leq \mathrm{d}<0.60 \mathrm{~mm}$ $\varpi 0.15 \mathrm{~mm} \leq \mathrm{d}<0.30 \mathrm{~mm}=0.075 \mathrm{~mm} \leq \mathrm{d}<0.15 \mathrm{~mm}=\mathrm{d}<0.075 \mathrm{~mm}$

(b) cyclic loading rockburst

Fig.3 Size distribution of sieve debris

\subsubsection{Characteristics of detritus from rockburst}

The ejection of coarse grained debris of biaxial rockburst test under impact loads from two adjacent surfaces is shown in Fig. 4. In the direction 2, there are 96 pieces of ejection coarse-grained debris, and the maximum length of which is $110 \mathrm{~mm}$, the maximum width is $100 \mathrm{~mm}$ and the maximum thickness is $13.3 \mathrm{~mm}$. In the direction 5 , there are 43 pieces of ejection coarse-grained debris, and the maximum length of which is $75 \mathrm{~mm}$, a maximum width of $55 \mathrm{~mm}$ and a maximum thickness of 9.5 mm.

The length and thickness ratio of the ejected coarse-grained debris along direction 2 and direction 5 have a certain range. Direction 2 is $2.16 \sim 9.57$, mainly in $3 \sim 7$, with a mean of 5.08, the representative size ratio for long, wide, thick $=4.96,3.64,3.64$, in which $5 \%$ is tabular clastic, only $21 \%$ is the flake debris; Direction 5 is $2.22 \sim 12.06$, mainly in $3 \sim 6$, with a mean of 5.27 , the representative size ratio for long, wide, thick $=5.12,3.73,1.00$, plate-like debris accounted for sixty percent, there are $18.6 \%$ of the flakes, flakes and massive debris are not more than $10 \%$.

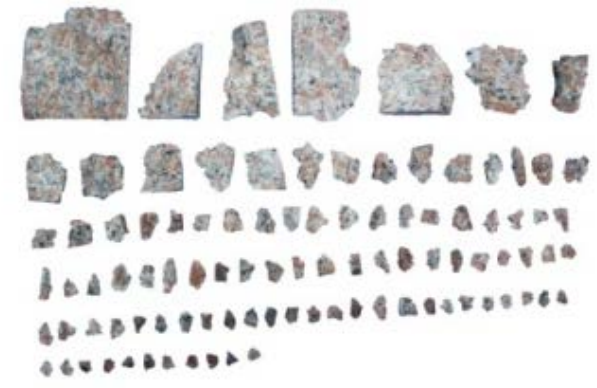

(a) direction 2

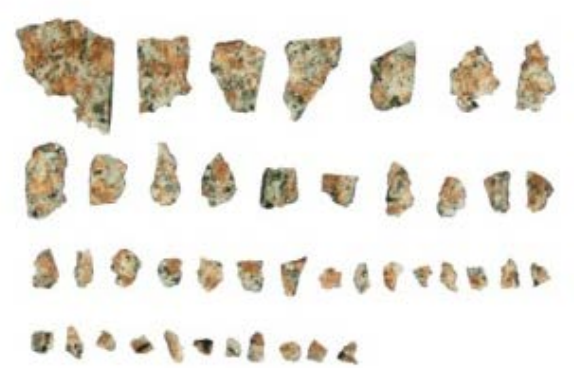

(b) direction 5

Fig.4 Ejection debris of rock burst test under impact loading

\subsubsection{Characteristics of cyclic loading ejection}

The ejected coarse-grained crumbs of two-axis rockburst test under cyclic loading on the two surface planes are shown in Fig. 5. There are 12 pieces of ejection debris in direction 2, the maximal length of 
the largest projectile is $77 \mathrm{~mm}$, the maximum width is $33 \mathrm{~mm}$ and the maximum thickness is $14.3 \mathrm{~mm}$. There are 48 pieces of ejection debris in direction 5 , the maximum length of the largest ejection fragment is $117 \mathrm{~mm}$, the maximum width is $67 \mathrm{~mm}$ and the maximum thickness is $4.3 \mathrm{~mm}$.

There is a certain variation range in the length and thickness ratio of the coarse-grained detritus in both directions D Direction 2 is 2.29 11.40, generally in 5 to 7, with a mean of 6.39, the direction of the representation of the size can be a long, wide, thick $=6.07,3.18,1.00$, mostly of them are plate and flake debris, and Accounting for $41.7 \%$ of them, block and flake-like debris were only $8.3 \%$ of them; Direction 5 is $4.03 \sim 26.59$, and more than 6 pieces accounted for $87.5 \%$, with an average value of 10.46, the representative size can be set to length: width: thickness $=9.77: 6.99: 1.00$, mostly belonging to flake debris and flake debris, each accounted for $27.1 \%$ and $60.4 \%$, containing $12.5 \%$ of the plate-like debris, no massive debris.

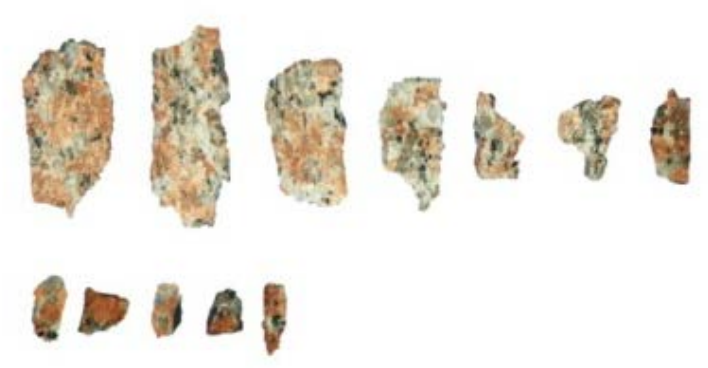

(a) direction2

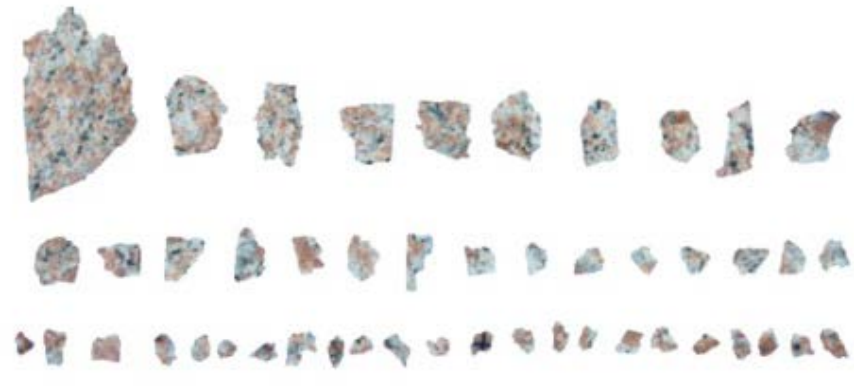

(b) direction5

Fig.5 Cyclic loading rockburst test ejection debris

\subsubsection{Characteristics of rockburst detritus in disturbed load}

Under the action of micro-perturbation, the two-axis rockburst test shows that the ejected coarse-grained debris of two surface planes is arranged according to the size shown in Fig.6. There are 78 ejection fragments in the direction 2, the maximum length of the largest ejection fragment is $83 \mathrm{~mm}$, the maximum width is $80 \mathrm{~mm}$, and the maximum thickness is $9.6 \mathrm{~mm}$. In the direction 5 , there are 28 ejection fragments with the largest maximum length of $84 \mathrm{~mm}$, the maximum width of $45 \mathrm{~mm}$ and the maximum thickness of $10.8 \mathrm{~mm}$.

There is a certain variable range of the length and thickness ratio of the two-direction ejecting coarse-grained debris. Direction 2 is $2.50 \sim 16.36$, generally $5 \sim 11$, the average value is 7.79 , the representative size ratio can be set as length: width: thickness $=7.33$ : $5.43: 1.00$, debris mainly belongs to the flake and flake-like debris, plate-like debris less than $21 \%$, almost no massive debris; direction 5 is $2.26 \sim 10.00$, generally $4 \sim 8$, the average value is 5.85 , the representative size ratio can be set as length: width: thickness $=5.44: 3.82$ : 1.00 , plate-like debris and flake debris mostly occupy $53.6 \%$ and $35.7 \%$, and there are very few massive debris and flaky debris.

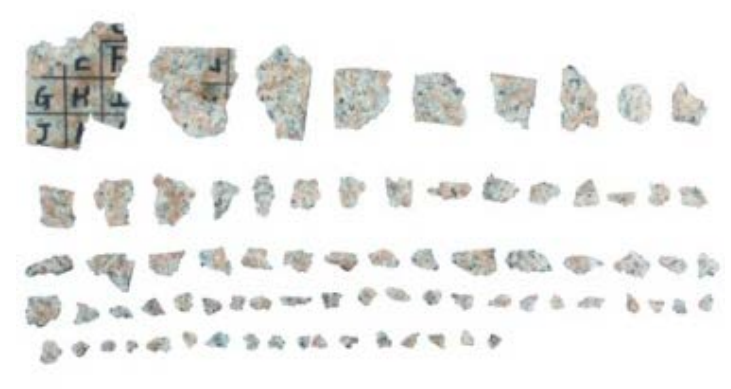

(a) direction2

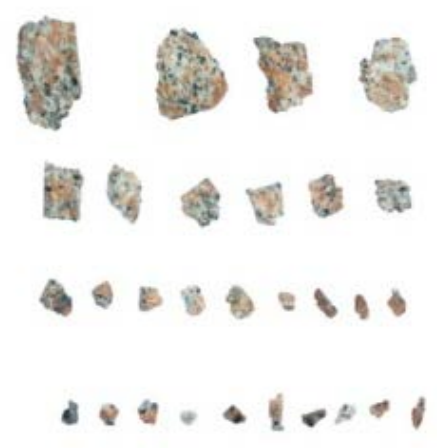

(b) direction5

Fig.6 Ejection debris of rockburst test by micro - disturbance loading 


\section{Conclusion}

The data of biaxial rockburst detritus with different loading types are obtained by using the self developed real triaxial rock burst test system, and the following conclusions are obtained:

(1) The total mass of rockburst detritus is significantly affected by the severity of rockburst loading, the static loading rock burst detritus is the smallest, only $1.06 \%$. The rockburst detritus is 13 times and 6 times more than that the static loading respectively under disturbance loading and cyclic loading. The mass of impact loading rock fragments is the largest in the study of different types of biaxial rockburst test, and the mass of ejected detritus accounts for $26.04 \%$ of the total mass of rock specimen, about 25 times of that of static loading.

(2) The size of ejection fragment has obvious change rule in different loading rockburst test, the rockburst of impact load is the largest, the second is disturbance loading, and the rockburst of static load is the smallest. For the ratio of representative sizes, the biaxial rockburst test of each loading type has obvious difference, the coarse-grained debris of the impact test is relatively uniform, the ratio of the representative size is smaller than other types of tests; the Length and width ratio of cyclic loading rockburst test is the most prominent.

(3) In the two-axis rockburst test under dynamic and static combined loading, the ejection coarse-grained debris mainly consisted of plate-like and sheet-like, impact test on two ejection direction slab clastic occupies $75 \%$ and $60 \%$ respectively, flake debris accounts for $21 \%$ and $21 \%$ respectively.

(4) In this paper, the characteristics of rockburst detritus are analyzed based on indoor rockburst test. Rockburst test is carried out on small scale rock specimen, and there are some differences in rock structure, stress condition and failure phenomenon compared with the actual project. In the future, it is necessary to strengthen the field research and further reveal the characteristics of rockburst detritus.

\section{Acknowledgment}

This work was financially supported by the Nation Science Foundation of China (Grant No.41472329).

\section{References}

[1] FENG Xia-ting, CHEN Bing-rui, ZHANG Chuan-qing, et al. Mechanism warning and dynamic control of rockburst development processes [M]. Beijing: Science Press, 2013: 1-3. (in Chinese)

[2] QIAN Qi-hu. Challenges faced by underground projects construction safety and countermeasures [J]. Chinese Journal of Rock Mechanics and Engineering, 2012, 31(10): 1945-1956. (in Chinese)

[3] XIE Heping, GAO Feng, ZHOUHongwei, et al. Fractal fracture and fragmentation in rocks[J]. Chinese Journal of Disaster Prevention and Mitigation Engineering. 2003, 23(4) : 1-9.(in Chinese)

[4] LI Xibing, GU Desheng. Rock impact dynamics [M]. Changsha: Central South University of Technology Press, 1994: 12. (in Chinese)

[5] HONG Liang. Size effect on strength and energy dissipation in fracture of rock under impact loads [Ph. D. Thesis][D]. Changsha: Central South University, 2008. (in Chinese)

[6] HE Manchao, YANG Guoxing, MIAO Jinli, et al. Classification and research methods of rockburst experimental fragments[J]. Chinese Journal of Rock Mechanics and Engineering, 2009, 28(8) : 1521-1530. (in Chinese)

[7] SHIVAKUMAR K, RAO M V M S, SRINIVASAN C, et al. Multifractal analysis of the spatial distribution of area rockburst at kolar gold mines[J]. International Journal of Rock Mechanics and Mining Sciences and Geomechanics Abstracts, 1996, 33(2): 167-172. 